Academic Platform Journal of Engineering and Science

\title{
Altın Geri Dönüşüm Prosesindeki Azot Oksit Emisyonunun Düşürülmesi
}

\author{
${ }^{* 1}$ Huzeyfe Özet, ${ }^{2}$ Banu Yeşim Büyükakıncı \\ ${ }^{1}$ İstanbul Aydın Üniversitesi, Fen Bilimleri Enstitüsü, İş Sağlığı ve Güvenliği Bölümü, İstanbul/ Türkiye \\ huzeyfeozet@gmail.com \\ ${ }^{2}$ İstanbul Aydın Üniversitesi, Mühendislik Fakültesi, Tekstil Mühendisliği Bölümü, İstanbul/Türkiye \\ yesimbuyukakinci@aydin.edu.tr
}

Araștırma Makalesi

Gelis Tarihi: 14.10.2019

Kabul Tarihi: 16.07 .2020

\section{$\ddot{O} z$}

Kuyumcu atölyelerinde, mücevherat yapımı süresince, çalışma ortamında toz olarak biriken altınının geri dönüşümü ramatçılar tarafından sağlanmaktadır. Altın geri dönüşümünün kral suyuyla (hidroklorik asit ve nitrik asit karışımı) yapıldığı cila ramatı metodunda oluşan azot oksit(NO), hem çalışma ortamında bulunmakta hem de atmosfere salınmaktadır. Bu tesislerde oluşan NO gazının giderilmesi için kostikle yıkama yapılmaktadır. NO gazının suda çözünürlüğü çok düşük olduğu için, alkali maddelerle yapılan sulu-yıkamalı filtreleme sistemi tek başına yeterli olmamaktadır. Bu çalışmada yapılan cila ramatı prosesinde, kral suyuna eklenen katı sülfamik asit ile NO oluşumu azaltılarak, ortama çevre ve insan sağlığı için zararsız olan nitröz oksit gazı $\left(\mathrm{N}_{2} \mathrm{O}\right)$ verilmiştir. Yapılan ölçümlerde NO parametresinin sıfır olduğu ve ortamda proses boyunca hiç bulunmadığı gözlemlenmiştir.

Anahtar Kelimeler: Altın geri dönüşümü, Cila ramatı, İş sağlığı ve güvenliği, Sülfamik asit

\section{Reduction of Nitric Oxide Emission in Gold Recycling Process}

\author{
${ }^{* 1}$ Huzeyfe Özet, ${ }^{2}$ Banu Yeşim Büyükakıncı \\ 1 İstanbul Aydın University, Institute of Science, Department of Occupational Health and Safety, İstanbul, Turkey \\ huzeyfeozet@gmail.com \\ 2 İstanbul Aydın University, Faculty of Engineering, Department of Textile Engineering, İstanbul/Türkiye \\ yesimbuyukakinci@aydin.edu.tr
}

\begin{abstract}
In jewelry workshops, during the production, the gold is accumulated as dust in the working environment. The recovery of these golden micro particles is provided by gold recycle workers. Nitric oxide is formed in a method called "polishing waste" which is the leaching process of gold within aqua regia (mixture of hydrochloric acid and nitric acid) for gold recovery. Nitric oxide is not only found in the working environment but also released into the atmosphere. Wet scrubbing with sodium hydroxide is used in order to eliminate NO gas, formed in the process. Since the water solubility of NO gas is very low, the wet scrubbing filtration system made with alkali materials is not sufficient alone. In this study, nitrous oxide gas $\left(\mathrm{N}_{2} \mathrm{O}\right)$, which is harmless to environment and human health, is given off to the atmosphere by reducing NO formation with addition of solid sulfamic acid to aqua regia. It was observed that NO parameter was zero and nitric oxide was not present at all during the process.
\end{abstract}

Keywords: Gold recovery, Polishing waste, Occupational health and safety, Sulfamic acid

\footnotetext{
*Sorumlu Yazar: Huzeyfe Özet, İstanbul Aydın Üniversitesi, Fen Bilimleri Enstitüsü, İş Sağlığı ve Güvenliği Doktora Öğrencisi, İstanbul, Türkiye huzeyfeozet@ gmail.com Telefon: 4441428/ 22603
} 


\section{GİRIŞ}

İlkçağlardan günümüze popülerliğini kaybetmeyen altına olan talep, gün geçtikçe artmaktadır. Türkiye altın rezervi bakımından Dünyada ilk sıralarda yer almasa da, mücevherat imalatında, İtalya'dan sonra hurda kullanımıyla birlikte Avrupa'da ikinci, Çin, Hindistan ve İtalya'dan sonra dünyada dördüncü sırada yer almaktadır. Türkiye Cumhuriyeti Ticaret Bakanlığ 1 , 2018 Mücevherat Sektör Raporu'na göre yılda 250-300 ton altın işlenmektedir. Üretim sırasında ciddi miktarlarda altın mikronize toz halinde tezgahlarda, zeminde, kiyafetlerde, el yıkama suyunda birikmektedir. Atölyede belirli aralıklarda toplanan ve ramat adı verilen bu altın tozu, kirlerden arındırılarak geri dönüşümü yapılmak üzere ramatçılara gönderilmektedir. Ramatçılar da çoğunlukla cila ramatı metoduyla kral suyuyla (hidroklorik asit ve nitrik asit karışımı) işledikleri altın ramatını, işlenebilir altın olarak sektöre geri kazandırmaktadırlar. 2006 yılına kadar Eminönü Kapalıçarşı'da ilkel yollarla çalışan ramatçılar, belediyece alınan kararla İkitelli Organize Sanayii' ne taşınmıştır. İş sağlığı ve güvenliği adına daha donanımlı olan bu tesisler Çevre ve Şehircilik Bakanlığınca kontrol edilmekte ve akredite laboratuvarlar tarafından düzenli gazbuhar emisyon ölçümleri yapılmaktadır.

Dünya Sağlık Örgütü'ne göre dış, hava kalitesinin düşük olması sigara içmekle hemen hemen aynı sağlık risklerini oluşturmaktadır. Dünya Sağlık Örgütü, 2019 yılı için sağlık açısından en önemli 10 tehdit arasında ilk sıraya hava kirliliğiyle birlikte iklim değişikliği sonucu ortaya çıkan sağlık sorunlarını yerleştirmiştir [1]. Ayrıca Türkiye Toraks Derneği 2016 yılında "Nefes Alamıyoruz" adlı sempozyumda, Türkiye'de hava kirliliği nedeniyle her yıl 32 bin kişinin öldüğünü ve ülkemizin 81 ilinin 80'inin havasının Dünya Sağlık Örgütü kriterlerine göre kirli olduğunu ve her yüz bin ölümün, 44'ünün hava kirliliği nedenli olduğunu, açıklamıştır [2].

Ülkemizde, 2008 yılında AB uyum sürecinde hazırlanan hava kalitesi yönetimine ilişkin usul ve esaslar, Hava Kalitesi Değerlendirme ve Yönetimi Yönetmeliği (HKDYY) ile belirlenmiştir. Ancak ülkemizde kabul edilen ulusal sınır değerler, hem Avrupa Birliği sınır değerlerine, hem de Dünya Sağlık Örgütü (DSÖ) hava kalitesi rehberlerinde yer alan sınır değerlere göre çok yüksektir. $\mathrm{Bu}$ yönetmelikle ülkemizin 2019 yılına kadar kademeli olarak hava kirleticilerinin parametrelerini azaltması ve en geç 2024'de de Avrupa Birliği limit değerlerine tamamen uyum sağlanması hedeflenmiştir.

TMMOB Çevre Mühendisleri Odası 2018 Hava Kirliliği Raporuna göre, endüstriyel tesislerin yoğun olduğu Başakşehir ilçesinin yıllık ortalama $\mathrm{NO}_{\mathrm{x}}$ (toplam $\mathrm{NO}$ ve $\mathrm{NO}_{2}$ ) sınır değeri $30 \mu \mathrm{g} / \mathrm{m} 3$ olması gerekirken, $56 \mu \mathrm{g} / \mathrm{m} 3$ olduğu görülmüştür [3]. Bu bölgede yer alan Çevre Sanayii Sitesi'nde tehlikeli kimyasallarla çalışan ramat tesisleri birlikte bulunmaktadır. Asit yağmurları ve solunum yolu hastalıkları gibi zararlı etkilerden çok daha fazlasına neden olan azot oksit(NO) ve azot dioksit $\left(\mathrm{NO}_{2}\right)$ gazlarının emisyon değerleri, bu sitede yer alan, pilot bir ramat tesisi seçilerek incelenmiştir. Akredite laboratuvar tarafından yapilan ölçüm raporunda $\mathrm{NO}_{\mathrm{x}}$ parametresinin $23,8 \mu \mathrm{g} / \mathrm{m} 3$ olduğu ve Bakanlık tarafindan belirlenen sınır değerin(30 $\mu \mathrm{g} / \mathrm{m}^{3}$ ) aşılmadığı görülmüştür. Ancak 2024 yılına kadar her yıl kademeli olarak düşürülecek $\mathrm{NO}_{\mathrm{x}}$ sınır değerlerinden dolayı bu parametrelerle ilgili iyileştirmelere ihtiyaç duyulmaktadır. Ayrıca, ramat tesislerinin aynı sanayii sitesinde yerleşik olduğu göz önünde bulundurulduğunda, genel ölçüm sonucuna olan etkisi azımsanamaz. İş sağlığı ve güvenliği açısından yapılan değerlendirmelerle, seçilen tesiste oluşan $\mathrm{NO}_{\mathrm{x}}$ değerinin, çalışma ortamında ve atmosfere salınımın daha düşük seviyeye indirilmesi amacıyla laboratuvar ortamında deneysel çalışmalar yapılmıştır. Bu çalışmayla oluşturulan kapalı sistem sayesinde çalışanlar, asit kabininden yayılan $\mathrm{NO}_{\mathrm{x}}$ gazlarına maruz kalmadıkları gibi, asit buharlarını solumamakta ve sıçrayan asit kaynaklı cilt tahrişinden de korunmaktadirlar.

\section{AZOT OKSITTLER}

\subsection{Azot Oksitlerin Özellikleri}

Azotun oksijenli bileşikleri, diazot oksit $\left(\mathrm{N}_{2} \mathrm{O}\right)$, azot monoksit(NO), azot dioksit $\left(\mathrm{NO}_{2}\right)$, diazo trioksit $\left(\mathrm{N}_{2} \mathrm{O}_{3}\right)$, diazot tetroksit $\left(\mathrm{N}_{2} \mathrm{O}_{4}\right)$, diazot pentoksittir $\left(\mathrm{N}_{2} \mathrm{O}_{5}\right) . \mathrm{NO}_{\mathrm{x}}$ ile gösterilen, $\mathrm{NO}$ (azot monoksit) ve $\mathrm{NO}_{2}$ (azot dioksit) hava kirliliği bakımından önemli olan azot oksitlerdir. 1770 de Joseph Priestley tarafından keşfedilen bu gazlardan NO, keskin kokulu, renksiz, suda çözünürlüğü çok düşük, erime noktas1 $163.6{ }^{\circ} \mathrm{C}$ ve kaynama noktas $1151.8{ }^{\circ} \mathrm{C}$ dir. $\mathrm{NO}$ elektron yapısından dolayı kolaylıkla hava olan ortamda oksijenle reaksiyona girerek $\mathrm{NO}_{2}$ yi oluşturur(Reaksiyon 1) [4].

$$
\begin{aligned}
& 2 \mathrm{NO}(\mathrm{g})+\mathrm{O}_{2}(\mathrm{~g}) \rightarrow 2 \mathrm{NO}_{2}(\mathrm{~g}) \\
& 2 \mathrm{NO}_{2}+\mathrm{H}_{2} \mathrm{O} \rightarrow \mathrm{HNO}_{3}+\mathrm{HNO}_{2}
\end{aligned}
$$

Azot dioksit ise kırmızıya yakın kahverengi renkli, keskin kokulu ve zehirli bir gazdır. Su ile reaksiyona girerek nitrik asit ve nitröz aside dönüşür (Reaksiyon 2). Koku alma alt sınır değeri 0.5 ppm'dir.

\section{2. Çalışma Yerlerinde Azot Oksitler ve Etkileri}

Azot oksitler endüstriyel tesislerde yoğun bir şekilde oluşmaktadır. Özellikle sülfürik asit elde edilmesinde, nitrik asit ve nitratların yapımında, boya ve patlayıcı maddelerin üretiminde, nitrosellüloz boya, yapay kumaşların formülasyonunda, gübre ve siyanamid yapımında görülmektedir. Ülkemizdeki çoğu endüstri kuruluşunda azot oksitler için yeterli arıtma sistemi mevcut değildir. Yeni yönetmeliklerin getirdiği yaptırımlar sonucu, yeni yapılan tesisler, limit değerlerinin altında emisyon salınımı sağlayamayan tesisler, arıtma/yıkama tesisleri kurmaktadırlar. Motorlu taşıtlardan çıkan egzoz gazlarıyla da çevreye $\mathrm{NO}_{x}$ gazları salınmaktadır. Egzoz gazlarında 
azot monoksit (NO) miktarı, azot dioksite $\left(\mathrm{NO}_{2}\right)$ göre daha fazladır [5].

İşyeri havasında $\mathrm{NO}_{2}$ 'nin eşik sınır değeri 5 ppm 'dir. Normal temiz hava saatlik $\mathrm{NO}_{2}$ eşik sınır değeri ise 0.25 ppm dir. Azot dioksit etkisini çok çabuk gösteren bir gazdır. 250-500 ppm $\mathrm{NO}_{2}{ }^{\prime} \mathrm{e}$ maruz kalan bir kimse koku ve görünüşünün farkına varmaksızın çok kısa süre içerisinde yaşamını kaybedebilir. Daha düşük dozları ise etki süresine göre ölümcül olabilir. Kronik zehirlenmede baş ağrısı, halsizlik, kabızlık, ağız ve yutak mukozasında ülserasyon görülür. Çalışanların işyerinde, 5 ppm $\mathrm{NO}_{2}$ in 4 saatlik maruziyeti sonucu, solunum sıklığg artarak tahribat etkisi görülmeye başlanır [5].

Azot gazlan (özellikle azot monoksit), methemoglobinemiye (hemoglobinin içeriğindeki iki değerli demirin, üç, değerli ferri haline dönüşmesi ve dokulara oksijen taşınamaması durumu) neden olabilir. $\mathrm{NO}_{2}$ miktarı yüksek şehir havasını soluyan çocuklarda akut bronşite ve yüksek methemoglobine rastlanmıştır. Methemoglobinemi kandaki toplam hemoglobinin, \%10 unu geçmesi siyanozise (morarma), \%30 unu geçmesi halsizlik, bulant1, akciğer ödemine, \%70 i geçmesi ise ölümlü vakalara neden olmaktadır [5,6].

\subsection{Azot Oksitlerin Ekosisteme Etkileri}

Atmosfer bünyesinde $\% 78$ oranında azot bulunmaktadır. Azotun yanması sonucunda ortaya çıkan azot oksitler $\left(\mathrm{NO}_{\mathrm{x}}\right)$ hava kirliliğine yol açan önemli emisyonlardır. Birçok ülkede olduğu gibi ülkemizde de belirlenen yönetmelikle bu kirleticilerin ölçülmesi, değerlendirilmesi ve önlemler alınması zorunludur. Dünya Sağlık Örgütü rehberinde yayınlanan ve Avrupa Birliği ülkelerince belirlenen $\mathrm{NO}_{2}$ standartlarıyla, ulusal sınır değerlerimiz kıyaslandığ durumda, parametrelerde farklılık görülmektedir (Tablo 1). Ancak, ülkemiz limit değerleri kademeli olarak her y1l düşürülerek en geç 2024'e kadar AB ile uyumlu olacaktır [3].

Tablo 1: Ülkemizde 2018 yılında uygulanan sınır değerler ile AB Ülkelerinde uygulanan ve Dünya Sağlık Örgütü tarafindan belirlenen sınır değerler [3,7]

\begin{tabular}{|c|c|c|c|}
\hline \multirow{2}{*}{$\begin{array}{l}\text { Ölçüm } \\
\text { Periyod } \\
\text { u }\end{array}$} & \multicolumn{3}{|c|}{ Sınır Değerler $\left(\mathrm{NO}_{2}\right)$} \\
\hline & $\begin{array}{l}\text { Türkiye'de } \\
\text { Uygulanan } \\
\text { (2018) }\end{array}$ & $\begin{array}{l}\text { AB } \\
\text { Ülkelerinde } \\
\text { Uygulanan }\end{array}$ & $\begin{array}{l}\text { Dünya } \\
\text { Sağlık } \\
\text { Örgütü }\end{array}$ \\
\hline Saatlik & $260 \mu \mathrm{g} / \mathrm{m}^{3}$ & $200 \mu \mathrm{g} / \mathrm{m}^{3}$ & $200 \mu \mathrm{g} / \mathrm{m}^{3}$ \\
\hline Yillık & $44 \mu \mathrm{g} / \mathrm{m}^{3}$ & $40 \mu \mathrm{g} / \mathrm{m}^{3}$ & $40 \mu \mathrm{g} / \mathrm{m}^{3}$ \\
\hline
\end{tabular}

Atmosfere salınan $\mathrm{NO}_{\mathrm{x}}$ değerinin çoğunlukla öncelikle azot monoksit(NO) fazında olması, endüstriyel tesislerin yoğun bulunduğu şehirlerde gerçekleşir [8]. Azot oksitler, atmosferin $\% 75$ 'inin toplandığ troposfer katmanında, hava kalitesini ciddi oranda düşüren fotokimyasal sis oluşuma neden olmaktadırlar. Atmosferin üst katmanlarında doğal olarak bulunan ozon $\left(\mathrm{O}_{3}\right)$, güneşten gelen mor ötesi 1şınları azaltan önemli bir gazdır. Ancak, troposfer katmanında güneş 1şığında, $\mathrm{NO}_{2}$ nin fotoliziyle zararlı hava kirleticisi olarak oluşmaktadır. Fotokimyasal dengeyle oluşan ozonun, $\mathrm{NO}$ ile reaksiyonuyla tekrar $\mathrm{NO}_{2}$ oluşmaktadır $[9,10]$.

$\mathrm{Bu}$ reaksiyonlar sırasında, ortamda bulunan hidrokarbon (HC), uçucu organik bileşikler (VOC) ve radikaller $\left(\mathrm{RO}_{2}\right)$ ozonun tüketimi tam gerçekleşmeden, $\mathrm{NO}_{2}$ oluşumunu sağlarlar. Fotokimyasal dengenin bozulmasıyla ozon seviyesinde artış olur. Biriken fazla ozonun, hava hareketleriyle dağılması sonucunda, fotokimyasal sis oluşmaktadır. Bu olayla yeryüzünde dolanan fazla ozon, ekosisteme ciddi zarar vererek insan, hayvan ve bitki sağlığına, malzemenin güvenliğine ve ömrüne olumsuz etkiler yapar. Gün ışığında tam yanmayan hidrokarbonlar ozon varlığında, azot oksitlerle PAN (peroksiasetil nitrat) oluşumunu sağlayarak, fotokimyasal siste yer alır [9].

$\mathrm{NO}_{2}$ havada bulunan nem ve su buharıyla birleşerek, bir dizi reaksiyon sonucu nitrik asit $\left(\mathrm{HNO}_{3}\right)$ oluşumunu sağlar. $\mathrm{Bu}$ asidik yap1 çiğ, sis, kar ve yağmurun ph seviyesini düşürerek asidifikasyonuna neden olur. Yeryüzüne inen bu hidrometeor asit yağışları, tarım alanlarını, ormanları, suda yaşayan canlıları, kısaca tüm çevreyi ve canlıları olumsuz etkilemektedirler [11]. Troposferde gerçekleşen bu fotokimyasal sis olayına Şekil 1' de yer verilmiştir.

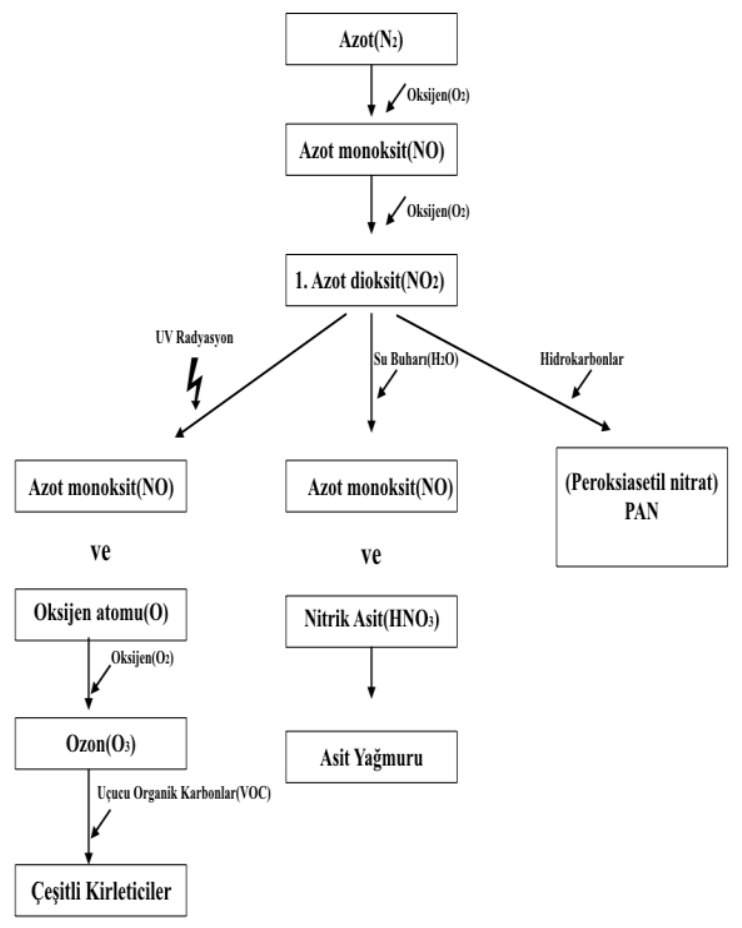

Şekil 1: Fotokimyasal sisin oluşumu [11] 


\section{CILA RAMATI PROSESI}

Kuyumcu atölyelerinde, mücevherat üretimi sirasında yapılan kesme, şekillendirme, eğeleme, cilalama gibi işlemlerde kopan mikronize altın parçacıkları tezgahlar, iş elbiseleri, duvarlar, yerdeki 1zgara araları, havalandırma filtresi gibi yerlerde birikirler. Düzenli aralıklarla toplanıp vakumlu torbalara koyulan, bu altın içerikli tozlara altın ramatı denilmektedir. Bu tozlardan altın geri kazanımını ramatçılar sağlarlar. Ramatçılık sektöründe farklı yöntemler kullanılsa da çoğunlukla, kral suyunun kullanıldığı cila ramatı metodu uygulanmaktadır. Cila ramatının genel işleyişi Şekil 2'de belirtilmiştir.

Atölyelerde biriktirilen altın içerikli toz ramatlar, ramatçılara torbalarla gönderilir. Öncelikle sanayii tipi firınlarda yakılarak organik kirlerden arındırılan altın ramatı, asit kabininde düzenli karıştırma ve ısıtma sağlanarak, kral suyuyla liç edilir.

Kral suyunda hurdanın çözümlendirilmesi sonucunda altın, platin, paladyum, bakır, kurşun ve kalay gibi metaller çözünerek sıvı faza geçer. Gümüş, klorür, rutenyum, iridyum, rodyum ve osmiyum ise çöker. Saf altının kral suyunda çözünmesi sonucu oluşan çözeltinin rengi sarıdır, yapıdaki bakır miktarına bağlı olarak ise sarımsı yeşile dönebilir.

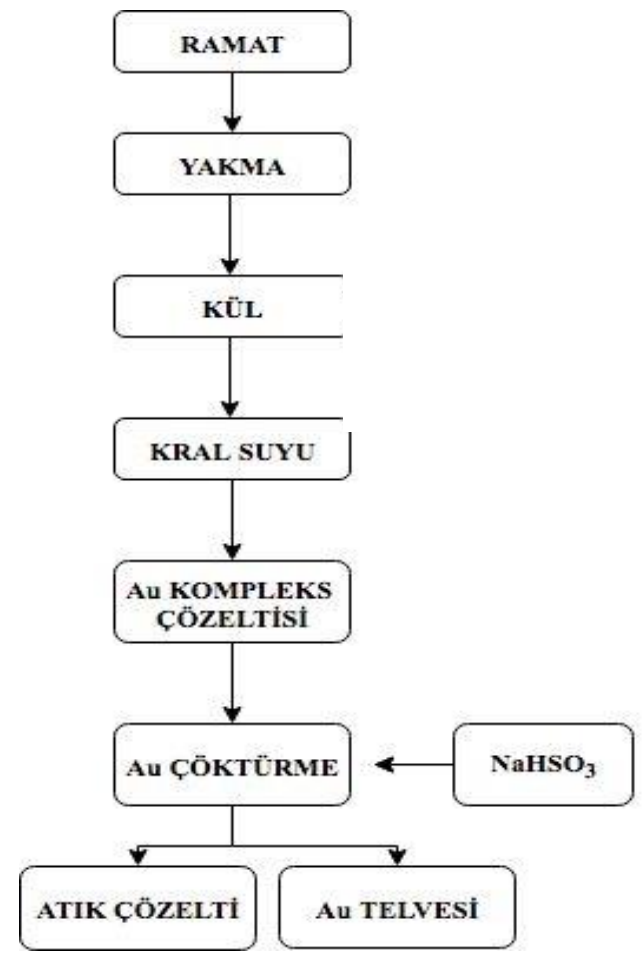

Şekil 2: Cila ramatı işleyişi akım şeması [12]

Kral suyu oluşumu ve altın ramatıyla gerçekleşen reaksiyon (Reaksiyon 3,4) aşağıda belirtilmiştir [12].

$\mathrm{HNO}_{3}+3 \mathrm{HCl} \rightarrow 2 \mathrm{H}_{2} \mathrm{O}+\mathrm{Cl}_{2}+\mathrm{NOCl}$
$\mathrm{Au}+4 \mathrm{HCl}+\mathrm{HNO}_{3} \rightarrow \mathrm{HAuCl}_{4}+\mathrm{NO}_{\mathrm{x}}+2 \mathrm{H}_{2} \mathrm{O}$

Kral suyunun oluşumu reaksiyonunda(Reaksiyon 3) nitrozil klorür ve klorür gazı oluşmuştur. Nitrozil klorürde kendi içinde [13];

$2 \mathrm{NOCI}_{(\mathrm{g})} \rightarrow 2 \mathrm{NO}_{(\mathrm{g})}+\mathrm{CI}_{2(\mathrm{~g})}$

$2 \mathrm{NO}_{(\mathrm{g})}+\mathrm{O}_{2}(\mathrm{~g}) \rightarrow 2 \mathrm{NO}_{2(\mathrm{~g})}$

azot monoksit ve klorüre dönüşmektedir. Azot monoksit ise atmosferdeki oksijenle reaksiyona girerek azot dioksit gazına dönüşmektedir (Reaksiyon 6). Oluşan çevre ve insan sağlığı için zararlı olan azot oksit (NO) ve azot dioksit $\left(\mathrm{NO}_{2}\right)$ gazları, $\operatorname{kostik}(\mathrm{NaOH})$ içerikli sulu-filtreme sistemiyle azaltıldıktan sonra atmosfere salınmaktadır. Altın ramatının kral suyuyla reaksiyonu sonucu, sıvı fazda bulunan altın ve diğer değerli metaller ile çamur halde çökenlerin tamamen ayrıştırılması için santrifüj makinesi kullanılmaktadır. Kükürt dioksit $\left(\mathrm{SO}_{2}\right)$, sodyum bisülfit $\left(\mathrm{NaHSO}_{3}\right)$, demir (II) sülfat $\left(\mathrm{FeSO}_{4}\right)$ gibi kimyasallarla kral suyunda bulunan altın çöktürülür. Redüksiyon için en yaygın kullanılan sodyum bisülfittir (Reaksiyon 7). Cila ramatı prosesi sonunda \%97- \%99 oranında altın geri kazanımı sağlanır [13].

$3 \mathrm{NaHSO}_{3}+2 \mathrm{HAuCl}_{4}+3 \mathrm{H}_{2} \mathrm{O} \rightarrow 3 \mathrm{NaHSO}_{4}+8 \mathrm{HCl}+2 \mathrm{Au}$ (7)

\section{MATARYEL VE METOT}

İstanbul'un Başakşehir ilçesinde, İkitelli Organize Çevre Sanayii'nde yer alan pilot bir ramat tesisi seçilerek, kral suyu metodunun iş sağlığı ve güvenliği açısından değerlendirmeleri yapılmıştır. $\mathrm{Bu}$ çalışma sonucunda yapılan işlemlerin optimizasyonu sağlanmıştır. Pilot tesis cila ramatı akım şemasında yer alan basamaklara göre işleyiş göstermektedir.

2.basamakta yer alan kral suyuyla altın ramatının reaksiyonun gerçekleştiği işlemde, asit kabininde bulunan kazanda karıştırma, el ile aralıklı olarak yaklaşık 1.5 saat boyunca yapılırken, çalışanlar tehlikeli asit buharlarını, proses gazlarını( $\mathrm{NO}$ ve $\mathrm{NO}_{2}$ ) solumakta ve sıçrayan kuvvetli asitlere maruz kalmaktadırlar (Şekil 3).

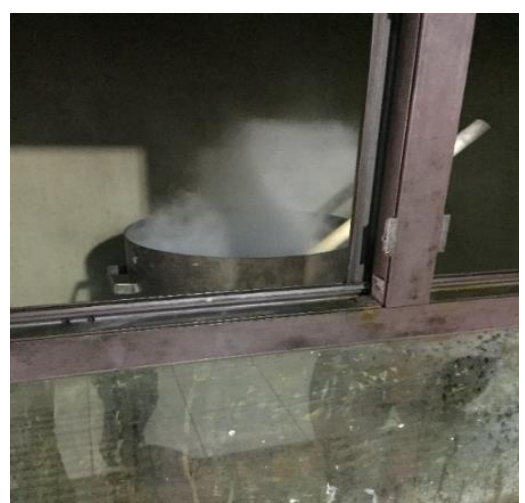

Şekil 3: Kral suyuyla altın ramatı reaksiyonun gerçekleştiği kazan 
Pilot ramat tesisinde gaz yıkama filtreme sistemi bulunmaktadır. Proses sonucu çıkan gazlar, filtreleme sisteminde bulunan sodyum hidroksitle $(\mathrm{NaOH})$ yıkanarak $\mathrm{NO}_{\mathrm{x}}$ emisyon parametresi düşürülmektedir. Emisyon değerleri akredite laboratuvar tarafindan düzenli ölçümler sağlanarak, raporlanmaktadır. $\mathrm{Bu}$ raporlara göre, $\mathrm{NO}_{x}$ emisyon değerleri $23.8 \mu \mathrm{g} / \mathrm{m}^{3}$ olduğu ve bakanlık tarafindan belirtilen sınır değerin $\left(30 \mu \mathrm{g} / \mathrm{m}^{3}\right)$ altında olduğu görülmüştür.

Cila ramatı metodunda kullanılan kral suyu prosesini, iş sağlığı ve güvenliği bakımından iyileştirmeler yapmak ve çevreye salınan $\mathrm{NO}_{\mathrm{x}}$ değerini daha da düşürmek için laboratuvar ortamında deneysel çalışmalar yapılmıştır.

Bu çalışmada kullanılan ekipmanlar;

- Manyetik karıştırıcılı balon 1sıtıcı,

- $1000 \mathrm{ml}$. cam reaksiyon balonu ve 4 boyunlu cam kapağ1,

- Kurutma borusu,

- Kapiler, civalı termometre ve adaptörü,

- Gaz yıkama şişesi,

- Penta NO ölçüm cihazı

- Laboratuvar tipi vakum pompasi,

- Bağlantılar için silikon hortumlar

Deneysel çalışmalarda da kral suyu hazırlamak için hidroklorik asit (\%35) ve nitrik asit (\%55), kral suyunda çözmek için 2 gr altın (24 ayar), reaksiyon sonu çıkan azot oksit gazının eliminasyonu için sülfamik asit $\left(\mathrm{H}_{3} \mathrm{NSO}_{3}\right)$, filtreleme için sodyum hidroksit $(\mathrm{NaOH})$, çözünen altının geri kazanımı için sodyum meta bisülfit ve altın testi için kalay klorür $\left(\mathrm{SnCl}_{2}\right)$ ve İndüktif eşleşmiş plazma-kütle spektrometresi (ICP-MS) kullanılmıştır.

Öncelikle ortamda oluşabilecek maksimum $\mathrm{NO}_{\mathrm{x}}$ değerinin ölçümü ve azot monoksit gaz-ölçer cihazın değerlendirilmesi için kontrol deneyi gerçekleştirilmiştir. $90{ }^{\circ} \mathrm{C}$ sicaklıkta, 1:3.5 oranında $\mathrm{HNO}_{3}$ ve $\mathrm{HCl}$ cam reaktörde karıştırılmasıyla oluşan kral suyunda, gaz düzenli olarak izlendiğinde, değer sürekli artarak 250ppm'e kadar yükselmiştir.

Kontrol deneylerinden sonra, Şekil 4' de gösterilen deneysel düzenek kapalı çeker ocak içerisinde hazırlanmıştır. Gaz yıkama şişesine, filtreleme için 1 molar $\mathrm{NaOH}$ çözeltisi hazırlanarak konulmuştur. Azot oksitlerin azaltılması için kullanılan alkali çözeltileri etkenliklerine göre aşağıda belirtilmiştir [14]. Ramat tesislerinde sodyum hidroksit kullanıldığı için (daha ekonomik olmasından dolayı), bu çalışmada da sodyum hidroksit çözeltisi tercih edilmiştir.

\section{$\mathrm{KOH}>\mathrm{NaOH}>\mathrm{NH}_{4} \mathrm{OH}>\mathrm{Na}_{2} \mathrm{CO}_{3}>\mathrm{K}_{2} \mathrm{CO}_{3}>\left(\mathrm{NH}_{4}\right)_{2} \mathrm{CO}_{3}$}

Cam reaksiyon balona öncelikle $11 \mathrm{M} \mathrm{HCl}$ asit çözeltisi ile 2 gram altın $(24 \mathrm{~K})$ koyulup, manyetik karıştırıcı ve ısıtıcı $\left(90{ }^{\circ} \mathrm{C}\right)$ açık hale getirilerek reaksiyonun hızlanması sağlanmıştır. $11 \mathrm{M} \mathrm{HNO}_{3}$ asit çözeltisi yavaşça eklenerek kral suyu oluşumu başlatılmıştır. Kısa süre sonra altın, kral suyu içerisinde çözünmüş ve kırmızı-kahverengi renkli NO ve $\mathrm{NO}_{2}$ gaz oluşumu başladığında, sülfamik asit $\left(\mathrm{H}_{3} \mathrm{NSO}_{3}\right)$ katı olarak eklenmiştir (Reaksiyon 9). Sülfamik asit eklenmesiyle kral suyunun oluşumunda ortaya çıkan nitrozil klorür miktarı(Reaksiyon 3) azaltılmıştır. Buna bağlı olarak oluşacak NO miktarı da düşürülmüştür (Reaksiyon 8). Ayrıca, bu reaksiyonda oluşan sülfürik asit $\left(\mathrm{H}_{2} \mathrm{SO}_{4}\right)$ ramatta kurşun bulunması durumunda, kurşunu çökerterek altından ayrıştırmaktadır (Reaksiyon 9). Bu adımda, eklenecek sülfamik asit miktarını belirlemek çok önemlidir. Fazla eklendiğinde altının bir kısmı çökeltiye geçerken, az eklenmesi $\mathrm{NO}_{\mathrm{x}}$ miktarının yeterince azalmamasına neden olmaktadır. Sülfamik asit, cam balondaki kral suyuna değişiklik gözlemlenmeyene kadar azar azar ilave edilmiştir.

$$
\begin{aligned}
& \mathrm{HNO}_{3}+\mathrm{H}_{3} \mathrm{NSO}_{3} \rightarrow \mathrm{H}_{2} \mathrm{SO}_{4}+\mathrm{N}_{2} \mathrm{O}+\mathrm{H}_{2} \mathrm{O} \\
& \mathrm{Pb}\left(\mathrm{NO}_{3}\right)_{2}+\mathrm{H}_{2} \mathrm{SO}_{4} \rightarrow \mathrm{PbSO}_{4} \downarrow+2 \mathrm{HNO}_{3}
\end{aligned}
$$

Tablo 2'de $\mathrm{NO}_{\mathrm{x}}$ için indirgeyici maddeler, yukarıdan aşağıya pahalılık ve etkenlik açısından sıralanmıştır [15]. Hidrazin en etken maddeyken en pahalı kimyasaldır. Ramatçılık sektörü finansal açıdan dar gelirli grubuna girdiğinden ve sülfamik asidin kolay bulunabilirliğinden dolayı sülfamik asit, indirgen madde olarak seçilmiştir.

Tablo 2: $\mathrm{NO}_{\mathrm{x}}$ eliminasyonu sağlayan yaygın amin grupları $\left(-\mathrm{NH}_{2}\right)$ [15]

\begin{tabular}{|ll|}
\hline Hidrazin & $\mathrm{N}_{2} \mathrm{H}_{2}$ \\
\hline Hidroksil amin & $\mathrm{HONH}_{2}$ \\
\hline Hidroksil amin Sülfat & $\left(\mathrm{HONH}_{2}\right)_{2} \cdot \mathrm{H}_{2} \mathrm{SO}_{4}$ \\
\hline Sülfamik Asit & $\mathrm{H}_{3} \mathrm{NSO}_{3}$ \\
\hline Üre & $\mathrm{H}_{2} \mathrm{~N} \cdot \mathrm{CO}_{2} \cdot \mathrm{NH}_{2}$ \\
\hline
\end{tabular}

Gaz çıkışı bitinceye yani reaksiyon tamamlanıncaya kadar azot oksit ölçer cihaz aktif halde tutulmuş ve izlenmiştir.

Reaksiyon cam balonunda oluşan sarımsı çözelti soğuduktan sonra, kral suyunda çözünmeyen maddelerden filtre kağıdıyla ayrıştırılmıştır. İçerisinde altın bulunan sarı çözeltideki altını çökertmek için, hazırlanan sodyum metabisülfit çözeltisi altın çözeltisine eklenmiştir. Tam çökeltinin oluşmasından sonra, $\mathrm{SnCl}_{2}$ ile çözeltide altın varlığı ön-kontrolü yapılmıştır. Yapılan çalışmada, çözeltideki altının tamamının çöktüğü belirlenmiştir. Daha sonra ileri analiz yapılarak çözeltideki olası altın varlığı tespit edilmiştir. BOREN Ar-Ge Merkezi Laboratuvarında, İndüktif eşleşmiş plazma-kütle spektrometresi (ICP-MS) ile yapılan analiz sonucunda çözeltide kalan altın miktarının $0.031 \mathrm{ppm}$ olduğu ve altının tamamının çötüğü belirlenmiştir (Tablo 3). 
Tablo 3: ICP-MS Analizi sonucu: Çözeltideki altın miktarı

\section{Analiz/Test Kodu: KA-02}

\begin{tabular}{|c|c|c|}
\hline $\begin{array}{c}\text { Numune Kayit } \\
\text { No }\end{array}$ & Numune lşaresi & $\begin{array}{c}\mathrm{Au} \\
\mathrm{ppb}\end{array}$ \\
\hline $20-\mathrm{H}-00067$ & Numune 1 (Au) & 0.031 \\
\hline
\end{tabular}

Daha sonra çökelti süzülüp, tamamıyla kuruduktan sonra tartılarak yüzde verimlilik hesaplanmıştır.

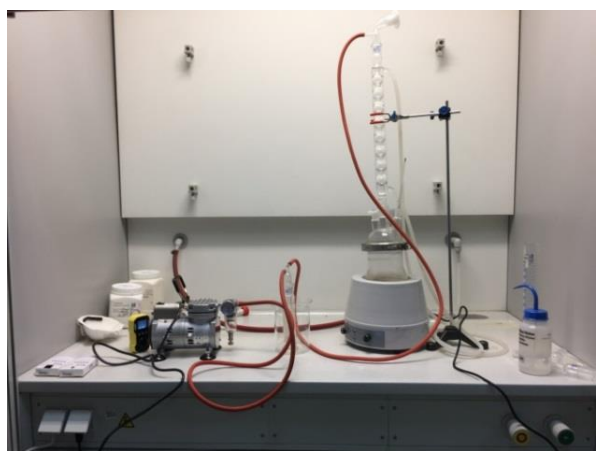

Şekil 4: Cila ramatının laboratuvar ortamında dizaynı

\section{BULGULAR}

Deneysel çalışmanın, kral suyuyla altın çözünmesi adımında, azot oksit ölçme cihazıyla düzenli olarak yapılan ölçüm, sıfır parametresini deney sonuna kadar, değişim olmadan göstermiştir. Proses ortamda azot oksit gazı oluşumu olmadan tamamlanmıştır.

Deney sonunda 1.983 gram saf altın elde edilmiştir.

Proses verimi;

2 gram $24 \mathrm{k}$ altın kitlesinin içerisinde 1.99 gr saf altın bulunduğundan

$1.983 / 1.99 \times 100=\% 99.6$ olarak hesaplanmıştır.

1.99 gram saf altını çözündürmek için, $1.95 \mathrm{ml} \mathrm{HNO}_{3}, 7 \mathrm{ml}$ $\mathrm{HCl}, 3$ gram katı sülfamik asit ve redüksiyon için 2 gram sodyum bisülfit $\left(\mathrm{NaHSO}_{3}\right)$ yeterli olmuştur.

Kral suyuna eklenen katı sülfamik asit, oluşan $\mathrm{NO}_{\mathrm{x}}$ miktarını düşürmektedir. Reaksiyon sonucunda ortaya çıkan diazot oksit $\left(\mathrm{N}_{2} \mathrm{O}\right)$ ise çevre ve insan sağlığı için zararsızdır. Ortamda çalışır halde bulunan NO ölçerle yapılan takipte, solunan havada azot oksitin hiç oluşmadığı tespit edilmiştir.

2 gram saf altın ile yapılan bu çalışmadan sonra altın miktarı azaltılarak deneyler tekrarlanmıştır. $1.5 \mathrm{~g}$ ve $1 \mathrm{~g}$ saf altının çözünmesi için kullanılan $\mathrm{HCl}$ ve $\mathrm{HNO}_{3}$ oranları benzerlik göstermiştir (Tablo 4).

Tablo 4: Saf altının çözünmesi için gerekli kral suyu miktarı

\begin{tabular}{|l|l|l|}
\hline Saf altın $(24 \mathrm{~K})$ & $\mathrm{HCl}(\mathrm{ml})$ & $\mathrm{HNO}_{3}(\mathrm{ml})$ \\
\hline 1 & 3.5 & 0.95 \\
\hline 1.5 & 5.2 & 1.40 \\
\hline 2 & 7.0 & 1.90 \\
\hline
\end{tabular}

Daha sonra, altının çözünmesinde sıcaklı̆̆ın etkisi araştırıııış ve $1.5 \mathrm{~g}$ saf altına 3 farklı sıcaklıkta $\left(30^{\circ} \mathrm{C}\right.$ $60^{\circ} \mathrm{C}-90^{\circ} \mathrm{C}$ ) kral suyu uygulanmıştır. Yapılan çalışmada, altının $90{ }^{\circ} \mathrm{C}$ de 1.5 saatte (90dk) tamamen çözündüğü tespit edilmiştir. $\mathrm{Bu}$ çözünme süresi $60^{\circ} \mathrm{C}$ de $105,30^{\circ} \mathrm{C}$ de ise 130 dakikaya çıkmıştır. Deney sıcaklığının yükseltilmesiyle altının çözünme hızının arttığı, gaz çıkışının da hızlandığı tespit edilmiştir.

\section{SONUÇ}

Cila ramat1 prosesinde, kullanılan kral suyundan dolayı çalışma ortamında oluşan ve atmosfere salınan $\mathrm{NO}_{\mathrm{x}}$ gazları insan sağlığını ve çevreyi tehdit etmektedir. Ramat evlerinde filtrasyon için kullanılan sodyum hidroksit içerikli sulu yıkama filtre sistemi azot oksit emisyonunu düşürmek için yeterli olamamaktadır. Bunun nedeni azot oksidin (NO) suda çözünürlüğünün çok düşük olmasıdır. Ayrıca çalışanlar, proses boyunca kuvvetli asidik yapılı kral suyunu el ile karıştırmakta ve ciddi tehlikelerle karşılaşmaktadırlar. İş sağlığı ve güvenliği adına yapılan optimizasyon çalışmaları sonucunda;

- Fazla kullanılan kimyasallar çevre ve insan sağlığını olumsuz etkilediğinden, $\mathrm{HNO}_{3}$ kullanımın asgari seviyede tutulması gerekmektedir. Ramat tesisinde 1 gram altını (24k) çözündürmek için ortalama $2 \mathrm{ml}$ nitrik asit kullanılırken, bu çalışmada uygulanan proses için $0.95 \mathrm{ml} \mathrm{HNO}_{3}$ yeterli olmuştur.

- Deney sıcaklığının yükseltilmesiyle altının çözünme hızının arttığı, gaz çıkışının da hızlandığı tespit edilmiştir.

- Cila ramatının kral suyuyla liç adımı sürecince, yapılan azot oksit ölçümünün sıfır "0" değerini göstermesi, sülfamik asit ile azot oksit indirgeme işleminin başarılı olduğunu kanıtlamaktadır.

- Proses sonunda \%99'un üzerinde altının geri dönüşümü sağlanmıştır. Bu sonuç, altın geri kazanımında sülfamik asit kullanımının olumlu bir etkisi olduğunu göstermektedir.

- Çalışanların sağlığını büyük ölçüde tehdit eden "cila ramatı prosesinin optimizasyonu iş sağlığı ve güvenliği açısından büyük önem arz etmektedir. Altının kral suyuyla çözünmesi işleminin kapalı sistemde, otomatik karıştırıcıyla yapilması sonucunda, çalı̧̧anlar asit kazanından siçrayan asitlere maruz kalmayacak, ortamdaki tehlikeli asit buharları ve gazlarını da solumayacaklardır.

\section{KAYNAKÇA}

[1] Who.int. (2019). Ten health issues WHO will tackle this year. https://www.who.int/emergencies/ten-threats-toglobal-health-in-2019 [Erişim zamanı;Ağustos, 10, 2019].

[2] Toraks.org.tr. (2019). Nefes Alamiyoruz: Partikül Madde Emisyonları Açısından Türkiye'de Hava Kirliliği | 
Türk Toraks Derneği. https://www.toraks.org.tr/news.aspx?detail=3772 [Erişim zamanı;A ğustos, 13, 2019].

[3] Odas1, T. (2019). \{ HAVA KIRLILIĞI RAPORU \} TMMOB Çevre Mühendisleri Odast. Cmo.org.tr.http://www.cmo.org.tr/genel/bizden_detay.php? kod $=97401 \&$ sube $=0$ [Erişim zamanı;Temmuz, 18, 2019].

[4] Earnshaw, A. and Greenwood, N. (2005). Chemistry of the elements. Amsterdam: Elsevier.

[5] Vural, N. (2005). Toksikoloji. Ankara Üniversitesi Eczacılık Fakültesi.

[6] Mansouri, A. (1985). Methemoglobinemia. The American Journal of the Medical Sciences, 289(5), pp.200209.

[7] Who.int. (2019). WHO | Air quality guidelines - global update 2005.

https://www.who.int/phe/health_topics/outdoorair/outdoora ir_aqg/en/ [Erişim zamanı;Ağustos,22, 2019].

[8] Warneck, P. (1999). Ch.9 Nitrogen Compounds in the Troposhere. In: Chemistry of the natural atmosphere, 71st ed. Elsevier.

[9] Çetin, Ş. and Ayberk, S. (2007). Azot Oksit Emisyonları ve Çevresel Açıdan Değerlendirilmesi. Endüstri Otomasyon Dergisi, 118, pp.22-26.
[10] Richter, A. (2009). Nitrogen oxides in the troposphere - What have we learned from satellite measurements?. The European Physical Journal Conferences, 1, pp.149-156.

[11] J. H. Withgott and S. R. Brennan, "Environment: The Science behind the Stories," Pearson. https://www.slideserve.com/tyne/lecture-outlines-chapter17-environment-the-science-behind-the-stories-4th-editionwithgott [Erişim zamanı;Eylül,11, 2019].

[12] Erdem, B. (2006). İkincil Kaynaklardan Altın Geri Kazanımı ve Rafinasyon Prosesinin Optimizasyonu. KimyaMetalürji Fakültesi, (yüksek lisans tezi). İTÜ, İstanbul/Türkiye.

[13] Gündeş, A. (2015). Altın Üretiminde Kullanılan Kral Suyundan Siv1 Gübre Üretimi. Kahramanmaraşs Sütçü Imam Üniversitesi Mühendislik Bilimleri Dergisi, 18(2), p.67.

[14] Kuropka, J. (2011). Removal of nitrogen oxides from flue gases in a packed column. Environment Protection Engineering, 37(1), pp.13-22.

[15] Lyne, E.G., Berryman, A.B., Evans, C.M., Sampat, S., Jensen-Holm, H., "Advances in NOx removal in smelter acid plants", Proc. Int. Seminar for New Initiatives in the Mining Sector) Chilean Copper Commission, Santiago (2002). 